\title{
Comparison of eligible non-enrolled patients and the randomised TWENTE trial population treated with Resolute and XIENCE V drug-eluting stents
}

\author{
Hanim Sen ${ }^{1}$, MD; Kenneth Tandjung ${ }^{1}$, MD; Mounir W.Z. Basalus ${ }^{1}$, MD; Marije M. Löwik ${ }^{1}$, PhD; Gert K. van \\ Houwelingen $^{1}$, MD; Martin G. Stoel ${ }^{1}$, MD; Hans W. Louwerenburg ${ }^{1}$, MD; Frits H.A.F. de Man ${ }^{1}$, MD, PhD; \\ Gerard C.M. Linssen ${ }^{3}$, MD, PhD; Rogier Nijhuis ${ }^{4}, \mathrm{MD}$, PhD; Mark B. Nienhuis ${ }^{5}$, MD, PhD; Patrick M.J. \\ Verhorst $^{1}, \mathrm{MD}, \mathrm{PhD}$; Job van der Palen ${ }^{6,7}, \mathrm{PhD}$; Clemens von Birgelen ${ }^{1,2 *}, \mathrm{MD}, \mathrm{PhD}$ \\ 1. Department of Cardiology, Thoraxcentrum Twente, Medisch Spectrum Twente, Enschede, The Netherlands; 2. MIRA, Institute \\ for Biomedical Technology and Technical Medicine, University of Twente, Enschede, The Netherlands; 3. Department of \\ Cardiology, Ziekenhuisgroep Twente, Almelo, The Netherlands; 4. Department of Cardiology, Ziekenhuisgroep Twente, Hengelo, \\ The Netherlands; 5. Department of Cardiology, Streekziekenhuis Koningin Beatrix, Winterswijk, The Netherlands ; 6. Department \\ of Epidemiology, Medisch Spectrum Twente, Enschede, The Netherlands; 7. Department of Research Methodology, Measurement \\ and Data Analysis, University of Twente, Enschede, The Netherlands
}

H. Sen and K. Tandjung contributed equally to this work.

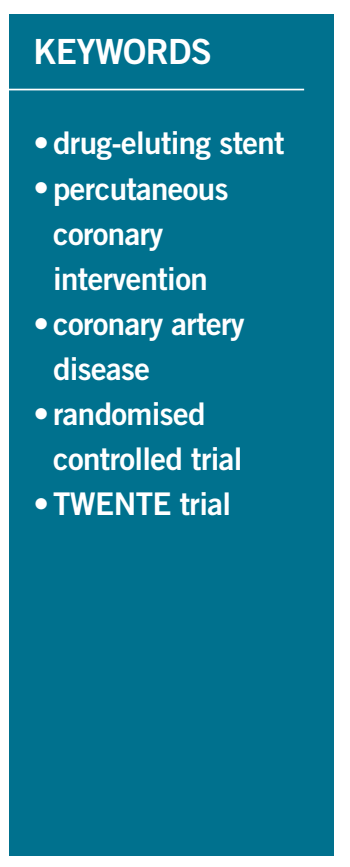

\begin{abstract}
Aims: The TWENTE trial recently enrolled more than $80 \%$ of all eligible patients, who were randomised to zotarolimus-eluting Resolute or everolimus-eluting XIENCE V stents. In the present study, we investigated whether eligible, non-enrolled patients differed from the randomised TWENTE trial population in baseline characteristics and one-year outcome.

Methods and results: Characteristics of 1,709 eligible patients were analysed. Independent external adjudication of clinical events was likewise performed for non-enrolled $(n=318)$ and randomised patients $(\mathrm{n}=1,391)$. Non-enrolled and randomised patients did not differ in gender distribution, diabetes mellitus, and clinical presentation, but differed significantly in age and cardiovascular history. Nevertheless, clinical outcome after one year did not differ in the primary composite endpoint target-vessel failure (TVF; $9.8 \%$ vs. $8.1 \% ; \mathrm{p}=0.34)$, and its components cardiac death ( $1.6 \%$ vs. $1.2 \% ; \mathrm{p}=0.61)$, target vessel-related myocardial infarction $(4.7 \%$ vs. $4.6 \%$; $=0.92)$, and target-vessel revascularisation $(3.8 \%$ vs. $3.0 \% ; \mathrm{p}=0.48)$. Previous bypass surgery predicted TVF in non-enrolled patients $(\mathrm{p}=0.001)$; removal of these patients resulted in identical TVF rates for non-enrolled and randomised patients ( $7.3 \%$ vs. $7.3 \%$; $\mathrm{p}=0.99)$.
\end{abstract}

Conclusions: Despite some differences in baseline characteristics, non-enrolled and randomised patients did not differ in one-year outcome, which was favourable for both populations and may be related to the drugeluting stents used.

\footnotetext{
*Corresponding author: Thoraxcentrum Twente, Department of Cardiology, MST, Haaksbergerstraat 55, 7513ER Enschede, The Netherlands.E-mail: c.vonbirgelen@mst.nl
} 


\section{Abbreviations}

$\begin{array}{ll}\text { CABG } & \text { coronary artery bypass grafting } \\ \text { DES } & \text { drug-eluting stent } \\ \text { PCI } & \text { percutaneous coronary intervention } \\ \text { STEMI } & \text { ST-elevation myocardial infarction } \\ \text { TVF } & \text { target-vessel failure } \\ \text { TVR } & \text { target-vessel revascularisation }\end{array}$

Non-STE-ACS non-ST-elevation acute coronary syndromes

\section{Introduction}

Drug-eluting stents (DES) have been rapidly adapted for routine percutaneous coronary interventions (PCI), as they reduced the need for reinterventions. ${ }^{1,2}$ As first-generation DES did not improve mortality, ${ }^{3-6}$ novel stents with different coatings were developed, aimed at improved clinical outcome. ${ }^{7,8}$ Two of these so-called second-generation DES are the zotarolimus-eluting Resolute stent (Medtronic, Minneapolis, MN, USA) and the everolimus-eluting XIENCE V stent (Abbott Vascular, Santa Clara, CA, USA). Both DES have thinstrut, open-cell, cobalt-chromium-based stent platforms and thin, durable polymer-based coatings, ${ }^{9,10}$ and they have shown favourable clinical results that have led to widespread use in clinical practice. ${ }^{11-16}$ For these stents, non-inferiority with regard to safety and efficacy was recently demonstrated by TWENTE, a randomised, controlled study in a patient population with advanced coronary disease and complex lesions, ${ }^{17}$ which confirmed with relatively low event rates the results of the RESOLUTE All-Comers trial. ${ }^{18}$ In addition, TWENTE is one of the relatively few randomised comparative DES trials that have been performed in a study population with very limited exclusion criteria to reflect routine clinical practice. ${ }^{18-21}$

The enrolment in the randomised TWENTE trial was high, comprising more than $80 \%$ of all eligible patients. ${ }^{17}$ However, it is unknown whether the non-enrolled patients, who were all likewise treated with Resolute and XIENCE V stents, differ from the randomised TWENTE trial population in terms of baseline characteristics or - perhaps even more relevant-in clinical outcome. To answer this question, we prospectively recorded comprehensive data sets on clinical, procedural, and angiographic characteristics of all eligible but non-enrolled patients in the Non-Enrolled TWENTE study. To assure high-quality clinical outcome data and to facilitate meaningful comparisons with the findings of the randomised TWENTE trial, an external clinical research organisation performed the independent adjudication of all clinical events together in both the Non-Enrolled TWENTE study and randomised TWENTE trial.

\section{Methods}

\section{STUDY DESIGN AND PATIENT POPULATIONS}

Details of the randomised TWENTE trial, which was performed from June 18, 2008 to August 26, 2010 at Thoraxcentrum Twente in Enschede, The Netherlands, have previously been reported. ${ }^{17}$ TWENTE is a randomised, controlled, patient-blinded DES trial, comparing Resolute and XIENCE V stents after 1:1 randomisation (ClinicalTrials.gov NCT01066650). Patients were eligible for enrolment and randomisation if they were aged 18 years or older, were capable of providing informed consent, and underwent a PCI with DES implantation for the treatment of chronic stable coronary artery disease or non-ST-elevation acute coronary syndromes (nonSTE-ACS). To include a broad study population, the study protocol defined no limit for lesion length, reference vessel size, and number of target lesions or vessels. The only exclusion criteria were: STelevation myocardial infarction (STEMI) or STEMI-equivalent requiring primary or rescue PCI during the past 48 hours; planned staged revascularisation; renal failure requiring haemodialysis; serious conditions that could limit the patient's ability to participate in study procedures, in particular life expectancy $<1$ year; participation in investigational drug or device study; if the choice of stent type was dictated by logistic reasons (e.g., a stent with required dimensions only available as one type). ${ }^{17}$

During the course of the randomised TWENTE trial, patients who were not enrolled were also treated with one of both, Resolute or XIENCE V stents, and their clinical course was prospectively registered as part of the Non-Enrolled TWENTE study. Operators were asked to report reasons for non-enrolment in PCI reports but incomplete documentation of this detail was not infrequent. We therefore used PCI reports, all clinical records, and interviews with the operators and other medical staff involved to obtain the most reliable estimate of the reasons for non-enrolment. The Non-Enrolled TWENTE study and the previously reported randomised TWENTE trial complied with the Declaration of Helsinki for investigation in human beings, and were performed after approval and supervision of our institutional ethics committee.

\section{INTERVENTION, MEDICATION, ELECTROCARDIOGRAPHY, AND LABORATORY TESTING}

PCI procedures were performed according to standard techniques as previously described. ${ }^{17}$ In brief, lesion predilatation, direct stenting, and/or stent postdilatation were permitted at the operators' discretion; liberal use of stent postdilatation was encouraged. Pharmacological therapy before, during, and after PCI as well as systematic laboratory and electrocardiographic testing were performed as previously described. ${ }^{17}$

\section{DEFINITIONS OF CLINICAL ENDPOINTS}

Definitions of clinical endpoints have been fully described in the main report on the randomised TWENTE trial. ${ }^{17}$ The same endpoint definitions were used in the present study. In general, the definitions of the Academic Research Consortium (ARC) were applied. ${ }^{22,23}$ In brief, the primary endpoint target-vessel failure (TVF) was defined as (in hierarchical order) cardiac death, target-vessel-related myocardial infarction, or clinically driven target-vessel revascularisation (TVR) by re-PCI or surgery. Cardiac death was defined as any death due to proximate cardiac cause, un-witnessed death and death of unknown cause, and all procedure-related deaths, including those related to concomitant treatment. Classification and location of myocardial infarction was performed based on laboratory testing, electrocardiographic parameters, angiographic information, and clinical data. ${ }^{17}$ Laboratory parameters for definition of myocardial infarction was any creatine kinase concentration of more than double the upper limit 
of normal with elevated values of a confirmatory cardiac biomarker. ${ }^{23}$ TVR was defined as any repeat coronary revascularisation of the target vessel. Target-vessel (or target-lesion) revascularisation was considered clinically indicated if the angiographic percent diameter stenosis of the then treated lesion was $\geq 50 \%$ in the presence of ischaemic signs or symptoms, or if the diameter stenosis was $\geq 70 \%$ irrespective of ischaemic signs or symptoms. ${ }^{22}$

Secondary clinical endpoints are: death from any cause; Q-wave and non-Q-wave myocardial infarction; any myocardial infarction; TVR by PCI, surgery, or either or both; clinically-indicated targetlesion revascularisation; any target-lesion revascularisation (stented segment including $5 \mathrm{~mm}$ proximal and distal border-zones); stent thrombosis, defined according to ARC. ${ }^{22}$ Composite parameters are (where applicable in a hierarchical order): Target-lesion failure, defined as a composite of cardiac death, target-vessel-related myocardial infarction, and clinically-indicated target-lesion revascularisation; and major adverse cardiac events, a composite of all-cause death, any myocardial infarction, emergent coronary artery bypass surgery or clinically indicated target lesion revascularisation.

\section{DATA ACQUISITION AND FOLLOW-UP}

In-hospital adverse events were recorded prior to discharge. As part of our centre's standard follow-up procedure, 12-month follow-up data of all patients were obtained at visits to outpatient clinics or, if not feasible, by telephone follow-up and/or a medical questionnaire. For any event trigger, members of the study team gathered all clinical information available from referring cardiologist, general practitioner, and/or hospital involved.

\section{INDEPENDENT CLINICAL EVENT ADJUDICATION}

Processing of clinical data and adjudication of adverse clinical events of the Non-Enrolled TWENTE population were performed independently in the same way as for the randomised TWENTE trial (use of anonymous patient data and blinding for stent type) by Cardialysis in Rotterdam, The Netherlands. In brief, the clinical event committee adjudicated any death, potential myocardial infarction, stent thrombosis, and revascularisation.

\section{STATISTICAL ANALYSIS}

Data analysis was performed with the Statistical Package for Social Sciences (SPSS, version 17; SPSS Inc., Chicago, IL, USA). Data were reported as frequencies and percentages for dichotomous and categorical variables and as mean \pm standard deviation for continue variables. The chi-square test and the Fisher's exact test were used as appropriate. The student's t-test was used to test normally distributed parameters. The Kaplan-Meier method was used to calculate the time to clinical endpoints and the Log-rank test was used to compare between-group differences. As non-enrolled patient populations are likely to contain more high-risk patients with a higher event rate, ${ }^{24}$ multiple logistic regression analysis was applied to the data of the non-enrolled patient population in order to identify predictors of TVF. In a subsequent analysis, we excluded patients with these variables to correct for potential confounders. Unless otherwise specified, a two-sided $\mathrm{p}$ value $<0.05$ was considered to indicate statistical significance.

\section{Results}

During the inclusion period of the randomised TWENTE trial, 2,239 patients were treated with DES at Thoraxcentrum Twente, The Netherlands. A total of 1,709 of these patients were eligible for study enrolment and randomisation. Finally, 1,391 of these 1,709 patients $(81.4 \%)$ with 2,116 lesions were enrolled in the randomised TWENTE trial. In other words, only 318 eligible patients $(18.6 \%$, with 466 lesions) were not enrolled in the randomised trial but were assessed in the Non-Enrolled TWENTE study (Figure 1).

Figure 1. Flow chart of patients treated with DES during the course of the randomised TWENTE trial. Patients of the Non-Enrolled TWENTE study and the randomised TWENTE trial were compared. *Data of the randomised TWENTE trial have previously been reported. ${ }^{17}$ 


\section{REASONS FOR NON-ENROLMENT}

Reasons for non-enrolment and estimates of their incidence within the non-enrolled population were: (1) refusal of the patient to participate in the randomised trial $(\sim 10 \%)$; (2) uncertainty of the operator whether the information transfer was successful (e.g., because of language barrier, deafness, or the entire clinical condition) ( 25\%); (3) logistic reasons (e.g., an ACS patient is not informed prior to the catheterisation, while another patient is announced for primary PCI) $(\sim 15 \%)$; and (4) omission of informing the patient about the trial prior to an elective procedure $(\sim 30 \%)$. This means that a substantial proportion of the eligible patients ( $\sim 20 \%$; i.e., $\sim 3.7 \%$ of all eligible patients) were not enrolled without evident reason.

\section{PATIENTS, TARGET LESIONS, AND PCI PROCEDURES}

Table 1 compares demographics and the procedural characteristics of both the Non-Enrolled TWENTE study population versus the

Table 1. Characteristics of patients and procedures.

\begin{tabular}{|c|c|c|c|}
\hline & $\begin{array}{l}\text { Non-enrolled } \\
\text { patients } \\
(\mathrm{N}=318)\end{array}$ & $\begin{array}{l}\text { Randomised } \\
\text { patients } \\
(\mathrm{N}=1,391)\end{array}$ & $p$-value \\
\hline Age (yrs ) & $66.0(10.9)$ & $64.2(10.8)$ & 0.01 \\
\hline Men & $224(70.4)$ & $1009(72.5)$ & 0.45 \\
\hline Diabetes mellitus (any) & $72(22.6)$ & $301(21.6)$ & 0.66 \\
\hline Chronic renal failure* & $21(6.6)$ & $38(2.7)$ & 0.001 \\
\hline Arterial hypertension & $185(58.2)$ & $773(55.6)$ & 0.40 \\
\hline Hypercholesterolaemia & $193(60.7)$ & $803 / 1357(59.2)$ & 0.06 \\
\hline Current smoker & $70(22.0)$ & $340(24.4)$ & 0.36 \\
\hline Family history of CAD & $102 / 193(52.8)$ & $740(53.2)$ & 0.93 \\
\hline Myocardinfarction (any) & $137(43.1)$ & $450(32.4)$ & $<0.001$ \\
\hline Previous PCl & $92(28.9)$ & $288(20.7)$ & 0.001 \\
\hline Previous CABG & $54(17.0)$ & $148(10.6)$ & 0.002 \\
\hline Clinical characteristic & & & 0.48 \\
\hline Stable angina pectoris & $151(47.5)$ & $674(48.5)$ & \\
\hline Acute coronary syndrome & $167(52.5)$ & $717(51.5)$ & \\
\hline Unstable angina & $84(26.4)$ & $325(23.4)$ & \\
\hline Non-ST-elevation MI & $83(26.1)$ & $392(28.2)$ & \\
\hline Left ventricular ejection fraction $<30 \% \pi$ & $13 / 199(6.5)$ & 32/1051 (3.0) & 0.015 \\
\hline Multivessel treatment & $61(19.2)$ & $336(24.2)$ & 0.06 \\
\hline Total no lesions treated per patient & & & 0.28 \\
\hline One lesion treated & $203(63.8)$ & $857(61.6)$ & \\
\hline Two lesions treated & $92(28.9)$ & $393(28.3)$ & \\
\hline Three of more lesions treated & $23(7.2)$ & $141(10.1)$ & \\
\hline At least one CTO & $28(8.8)$ & $95(6.8)$ & 0.22 \\
\hline At least one bifurcation & $83(26.1)$ & $362(26.0)$ & 0.98 \\
\hline At least one in-stent restenosis & $43(13.5)$ & $69(5.0)$ & $<0.001$ \\
\hline Postdilatation & $278(87.4)$ & $1222(87.9)$ & 0.83 \\
\hline \multicolumn{4}{|c|}{$\begin{array}{l}\text { Data are number (\%) or mean (SD); CAD: coronary artery disease; PCI: percutaneous coronary } \\
\text { intervention; CABG: coronary artery bypass grafting; MI: myocardial infarction; CTO: chronic } \\
\text { total occlusion; * Chronic renal failure was defined by serum creatinine level } \geq 130 \mu \text { mol/L; } \\
\text { "Left ventricular ejection fraction was assessed with ultrasound, MRI or LV angiography }\end{array}$} \\
\hline
\end{tabular}

randomised TWENTE trial population. Both study populations did not differ in the proportion of genders, diabetes mellitus, and clinical presentation (acute coronary syndromes in $52.5 \%$ vs. $51.5 \%$, respectively; $\mathrm{p}=0.48)$. Non-enrolled patients were somewhat older ( $66.0 \pm 10.9$ vs. $64.2 \pm 10.8$ years; $p=0.01)$. There was a trend towards less multivessel treatment in the non-enrolled patients $(19.2 \% \mathrm{vs}$. $24.2 \%$; $p=0.06$ ), matching with a more severely impaired left ventricular $(6.5 \%$ vs. $3.0 \% ; \mathrm{p}=0.015)$ and renal function $(6.6 \%$ vs. $2.7 \% ; \mathrm{p}=0.001)$ in this group. In addition, non-enrolled patients more often had a history of previous MI (43.1\% vs. $32.4 \%$; $\mathrm{p}<0.001)$, previous PCI $(28.9 \%$ vs. $20.7 \%$; $\mathrm{p}=0.001)$, and previous coronary artery bypass grafting $(\mathrm{CABG})(17.0 \%$ vs. $10.6 \%$; $\mathrm{p}=0.002$; Table 1). A total of 466 and 2,116 lesions were treated in the NonEnrolled TWENTE study and the randomised TWENTE trial, respectively (Table 2). Target lesions of non-enrolled patients more often showed complex B2 or C lesion types (76.1\% vs. $70.1 \%$; $\mathrm{p}=0.047)$. In parallel with the higher incidence of a history of PCI and/or CABG in the Non-Enrolled TWENTE population, more target lesions were restenoses and bypass graft lesions ( $p<0.001$ for both; Table 2).

\section{CLINICAL OUTCOME}

Clinical follow-up data were available for 316 patients of the NonEnrolled TWENTE study (99.4\% follow-up data) and 1,387 randomised TWENTE patients (100\% follow-up data available; four patients withdrew consent). Table $\mathbf{3}$ and Figure $\mathbf{2}$ show various clinical outcome parameters at one-year follow-up. Between both populations, there was no significant difference in the primary outcome parameter TVF ( $9.8 \%$ vs. $8.1 \%$; $\mathrm{p}=0.34$, OR 1.23 [95\% CI 0.81 to 1.8$]$ ).

Table 2. Lesion characteristics.

\begin{tabular}{|l|c|c|c|}
\hline Target lesion coronary artery & $\begin{array}{c}\text { Non-enrolled } \\
\text { (N=466 } \\
\text { lesions) }\end{array}$ & $\begin{array}{c}\text { Randomised } \\
\text { (N=2,116 } \\
\text { lesions) }\end{array}$ & $\boldsymbol{p}$-value \\
\hline Left main & $17(3.6)$ & $54(2.6)$ & 0.19 \\
\hline Left anterior descendens & $179(38.4)$ & $878(41.5)$ & 0.22 \\
\hline Left circumflex & $107(23.0)$ & $483(22.8)$ & 0.95 \\
\hline Right coronary artery & $135(29.0)$ & $653(30.9)$ & 0.42 \\
\hline Bypass graft & $28(6.0)$ & $48(2.3)$ & $<0.001$ \\
\hline ACC-AHA lesion class & & & 0.047 \\
\hline A & $24(5.2)$ & $154(7.3)$ & \\
\hline B1 & $87(18.7)$ & $478(22.6)$ & \\
\hline B2 & $153(32.8)$ & $678(32.0)$ & \\
\hline C & $202(43.3)$ & $806(38.1)$ & \\
\hline De novo lesions & $409(87.8)$ & $1999(94.5)$ & $<0.001$ \\
\hline Chronic total occlusion & $30(6.4)$ & $100(4.7)$ & 0.13 \\
\hline In stent restenosis & $37(7.9)$ & $75(3.5)$ & $<0.001$ \\
\hline Bifurcated lesion & $101(21.7)$ & $518(24.5)$ & 0.20 \\
\hline
\end{tabular}

Data are number (\%); ACC: American College of Cardiology; AHA: American Heart Association; De novo lesions include chronic total occlusion, but not grafts and in-stent restenosis 
Table 3. Clinical outcome after one year.

\begin{tabular}{|c|c|c|c|}
\hline & $\begin{array}{l}\text { Non-enrolled } \\
\text { patients } \\
(\mathrm{N}=316)\end{array}$ & $\begin{array}{c}\text { Randomised } \\
\text { patients } \\
(\mathrm{N}=1,387)\end{array}$ & $p$-value \\
\hline Target vessel failure & $31(9.8)$ & $113(8.1)$ & 0.34 \\
\hline \multicolumn{4}{|l|}{ Death } \\
\hline Any cause & $7(2.2)$ & $29(2.1)$ & 0.89 \\
\hline Cardiac cause & $5(1.6)$ & $17(1.2)$ & 0.61 \\
\hline \multicolumn{4}{|l|}{ Target vessel related MI } \\
\hline Any & $15(4.7)$ & $64(4.6)$ & 0.92 \\
\hline Q-wave & 0 & $11(0.8)$ & 0.11 \\
\hline Non-Q-wave & $15(4.7)$ & $53(3.8)$ & 0.45 \\
\hline Periprocedural MI & $13(4.1)$ & $57(4.1)$ & 0.99 \\
\hline \multicolumn{4}{|l|}{ Clinically indicated TVR } \\
\hline Any & $12(3.8)$ & $42(3.0)$ & 0.48 \\
\hline Percutaneous & $12(3.8)$ & $33(2.4)$ & 0.16 \\
\hline Surgical & 0 & $9(0.6)$ & 0.15 \\
\hline Target lesion failure & $28(8.9)$ & $102(7.4)$ & 0.36 \\
\hline \multicolumn{4}{|l|}{ Clinically indicated TLR } \\
\hline Any & $9(2.8)$ & $29(2.1)$ & 0.41 \\
\hline Percutaneous & $9(2.8)$ & $22(1.6)$ & 0.13 \\
\hline Surgical & 0 & $7(0.5)$ & 0.21 \\
\hline $\begin{array}{l}\text { Death from cardiac causes or } \\
\text { target-vessel MI }\end{array}$ & $20(6.3)$ & $67(4.8)$ & 0.28 \\
\hline Major adverse cardiac events & $30(9.5)$ & $132(9.5)$ & 0.99 \\
\hline \multicolumn{4}{|l|}{ Definite ST (0-360 days) } \\
\hline all patients & 0 & $4(0.6)$ & 0.34 \\
\hline \multicolumn{4}{|l|}{ Probable ST (0-360 days) } \\
\hline all patients & $1(0.3)$ & $10(0.7)$ & 0.42 \\
\hline \multicolumn{4}{|l|}{ ST (0-360 days) } \\
\hline Possible & $3(0.9)$ & $6(0.4)$ & 0.25 \\
\hline Definite or probable & $1(0.3)$ & $14(1.0)$ & 0.23 \\
\hline Definite, probable or possible & $4(1.3)$ & $20(1.4)$ & 0.81 \\
\hline
\end{tabular}

Data are number of patients (\%); MI: myocardial infarction; TVR: target vessel revascularisation; TLR: target lesion revascularisation; ST: stent thrombosis; Major adverse cardiac events is a composite of all cause death, any myocardial infarction, emergent coronary-artery bypass surgery or clinically indicated target lesion revascularisation

There was also no significant difference in the components of the primary endpoint (cardiac death $[1.6 \%$ vs. $1.2 \%$; $=0.61]$; target vessel-related MI $[4.7 \%$ vs. $4.6 \%$; $=0.92]$; and clinically driven TVR [3.8\% vs. $3.0 \%$; $=0.48]$ ), and any other clinical endpoint, such as death from any cause $(2.2 \%$ vs. $2.1 \% ; \mathrm{p}=0.89)$ and major adverse cardiac events (9.5\% vs. $9.5 \%$; $\mathrm{p}=0.99$; Table 3).

\section{STENT THROMBOSIS}

Within the non-enrolled patient population, there was no definite stent thrombosis (Table 3). Definite or probable stent thrombosis occurred in one patient of the Non-Enrolled TWENTE population (one probable stent thrombosis) and in 14 patients of the randomised TWENTE trial population $(0.3 \%$ vs. $1.0 \%$; $=0.23)$.

\section{PREDICTORS OF TARGET VESSEL FAILURE}

The only parameter that significantly predicted TVF in the NonEnrolled TWENTE population was a history of CABG (OR 3.7, 95\% CI 1.67-8.15; $\mathrm{p}=0.001$ ). After removal of patients with a history of CABG from the analyses (54/316 non-enrolled [17\%] and 148/1,386 randomised patients [10.6\%]), differences in baseline characteristics were virtually unchanged: the Non-Enrolled TWENTE population still comprised older patients $(65.3 \pm 11.1$ vs. $63.7 \pm 10.9$ years; $p=0.03)$ and more patients with severely impaired left ventricular function (6.2\% vs. $2.6 \%$; $=0.02)$, impaired renal function (5.3\% vs. $2.6 \%$; $\mathrm{p}=0.02)$, history of previous MI $(42.8 \%$ vs. $31.5 \% ; \mathrm{p}<0.001)$, and history of previous PCI $(24.6 \%$ vs. $18.8 \%$; p=0.03). However, removal of patients with a history of CABG resulted in identical TVF rates for Non-Enrolled TWENTE patients and the randomised TWENTE population (7.3\% [19/262] vs. 7.3\% [90/1,239]; $\mathrm{p}=0.99)$. Moreover, the slight numerical differences in other clinical endpoints continued to be statistically non-significant (major adverse cardiac events $8.0 \%[21 / 262]$ vs. $8.6 \%[106 / 1,239] ; p=0.78)$.

\section{Discussion}

In the present study, we addressed the question of whether patients, who were not enrolled in the randomised TWENTE trial ${ }^{17}$ but were all likewise treated with Resolute or XIENCE V stents, differed from the enrolled and randomised patients in baseline characteristics, procedural details, or clinical outcome. During the course of the randomised TWENTE trial, only 19 percent of the eligible patients were not enrolled in the randomised trial. ${ }^{17}$ To assure high-quality clinical outcome data and to facilitate meaningful comparisons, an independent external clinical research organisation performed the clinical event adjudication for both the Non-Enrolled TWENTE population and the randomised TWENTE population (together in the same adjudication session). The randomised TWENTE population comprised many complex patients and advanced coronary lesions, ${ }^{17}$ and in the Non-Enrolled TWENTE population many patients showed similar baseline characteristics and cardiovascular risk factors. Nevertheless, Non-Enrolled TWENTE patients were on average slightly older and more frequently showed a history of previous myocardial infarction and/or coronary revascularisations. As a consequence, we also identified mild but statistically significant differences in the rates of heart failure, renal failure, and lesion complexity in favour of the randomised TWENTE trial population, which comprised less bypass graft lesions and restenoses.

Despite the slight aforementioned baseline differences, the NonEnrolled TWENTE population and the randomised TWENTE trial patients showed no significant difference in clinical outcome parameters such as TVF $(9.8 \%$ vs. $8.1 \%$; $\mathrm{p}=0.34)$, all-cause mortality $(2.2 \%$ vs. $2.1 \%$; $=0.89)$, or major adverse cardiac events $(9.5 \%$ vs. $9.5 \%$; $=0.99$ ). Our data suggest that if all 1,709 consecutive eligible patients had entered the randomised trial, the overall TVF rate could have been as low as $8.5 \%$. In fact, this study underlines the high clinical performance of the second-generation DES that were used. This performance appears to be greatly independent of the clinical profile of the patients. 

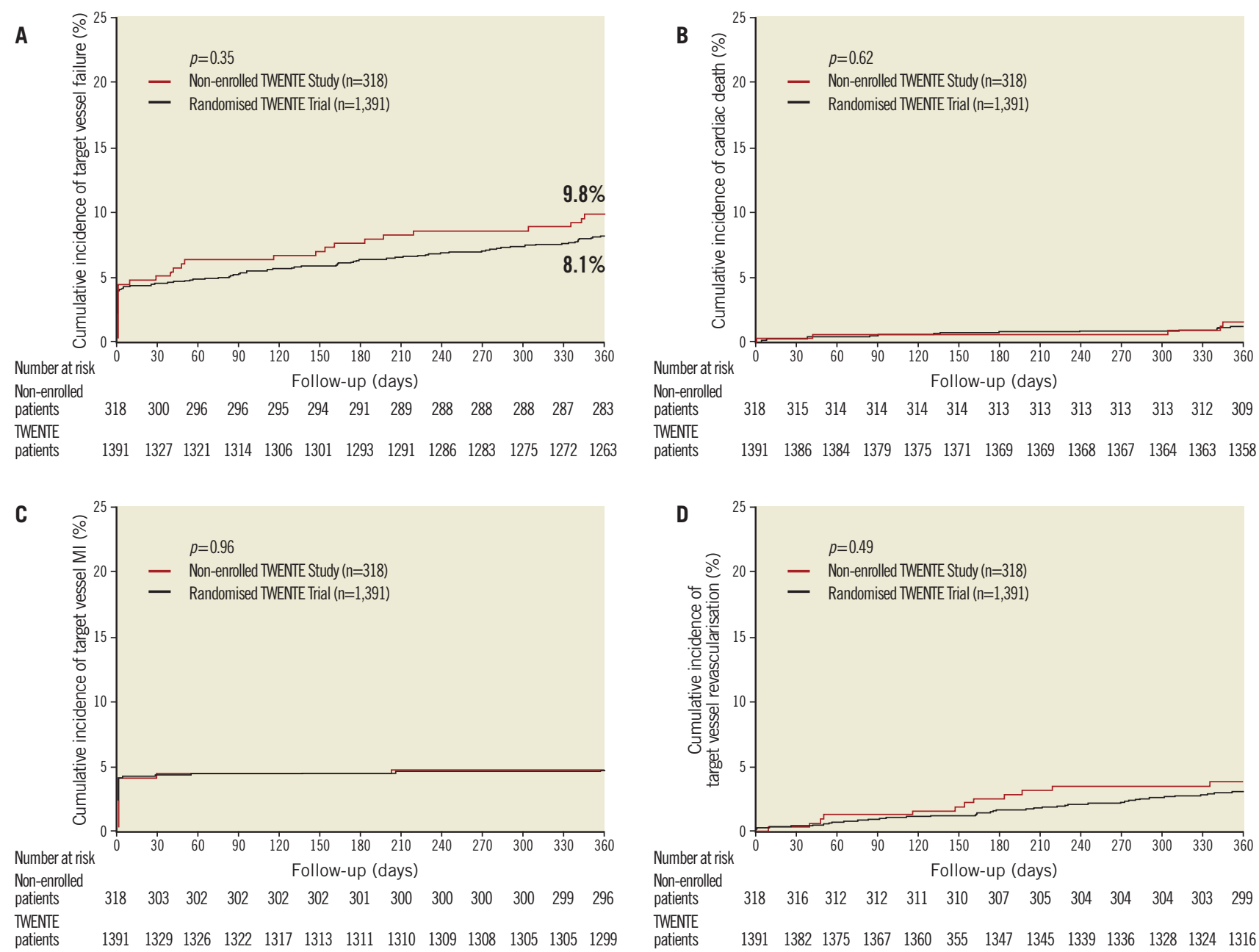

Figure 2. Kaplan-Meier for the primary endpoint and the individual components of the primary endpoint. Kaplan-Meier cumulative incidence curves at one year for the primary endpoint target-vessel failure, a composite of cardiac death, target-vessel related myocardial infarction, or target-vessel revascularisation (A); cardiac death (B); myocardial infarction (C); and target-vessel revascularisation (D) for both patients of the Non-Enrolled TWENTE study and of the randomised TWENTE trial.

\section{COMPARISON WITH PREVIOUS STUDIES}

Compared to RESOLUTE All-Comers trial ${ }^{18}$ and COMPARE trial, ${ }^{20}$ two randomised studies with second-generation DES in "real-world" patient populations, the randomised TWENTE patients showed similar or slightly higher rates of previous MI (32.4\% vs. $16.5-29.7 \%)$, previous PCI (20.7\% vs. $13.5-32 \%)$, previous CABG (10.6\% vs. 6.5-9.8\%), heart failure (3.0\% vs. $2.5 \%)$, in-stent restenosis lesions (5.0\% vs. 2.5-8.1\%), bypass graft lesions $(2.3 \%$ vs. $2.0-2.5 \%)$, and their age was similar (mean age 64.2 vs. 63.3-64.3 years). Accordingly, it is fair to state that the randomised TWENTE trial" is a study in a "real-world" patient population (with the exception of acute STEMI), providing data that is highly relevant for routine clinical practice.

Analyses of randomised intervention studies that compared PCI and $\mathrm{CABG}$ have demonstrated that patient characteristics and the clinical outcome of these studies differed significantly from routine clinical practice. ${ }^{24}$ Selection bias is more likely to be undetectable in studies with low enrolment rates, but in the randomised TWENTE trial the enrolment rate was particularly high. In many Non-Enrolled TWENTE patients there was at least one reason for non-enrolment. Nevertheless, in approximately $3.7 \%$ of all eligible patients the main reason for non-enrolment could not be identified. This leaves room for potential selection bias, and in fact, the differences in baseline characteristics between the Non-Enrolled TWENTE study population and the randomised TWENTE trial patients suggest that there could have been some selection bias. Examples of patients whom operators may deliberately not enrol in a randomised trial are patients with target vessels that supply previously (partly) infarcted myocardium because persistent electrocardiographic changes may render the diagnosis of a subsequent myocardial infarction difficult and sometimes impossible. The same may apply to certain patients with previous $\mathrm{CABG}$ and end-stage coronary artery disease, who likewise often have a higher cardiovascular risk profile and an advanced age. 
But what is known about eligible patients who were not enrolled in other randomised, comparative DES trials with "real-world" patient populations? In fact, such information is sparse. However, de Boer et al recently reported for their high-volume PCI centre baseline characteristics and one-year all-cause mortality of patients who participated in two randomised multicentre trials in all comers and compared it to non-participating PCI patients (579 patients enrolled vs. 663 non-participants). ${ }^{25}$ In that study, baseline characteristics differed significantly between trial participants and nonparticipants, who were older and had a higher incidence of heart failure and unstable clinical syndromes than trial participants). ${ }^{25}$ In addition, all-cause mortality at one-year follow-up was significantly higher in non-participants $(6.9 \%$ vs. $3.1 \%$; $p=0.002)$.

Of note, these all-comers trials included patients with acute STEMI, ${ }^{18,19,25}$ which - on average - have a higher mortality risk. On the contrary, the randomised TWENTE trial did not enrol patients with acute STEMI, ${ }^{17}$ who consequently were also not assessed in the Non-Enrolled TWENTE study. In addition, de Boer et al addressed all non-participating PCI patients, including those who had clear contraindications for participation in one of the two randomised trials (e.g., patients in shock with very high mortality risk), ${ }^{25}$ while our own study examined only eligible patients who all fulfilled the inclusion criteria of the randomised TWENTE trial. ${ }^{17}$ This may explain differences in all-cause mortality between non-participants of the study of de Boer et al and the Non-Enrolled TWENTE population. A comparison of clinical outcome parameters other than mortality was not possible, as no such data were available for non-enrolled patients of other randomised comparative DES trials.

\section{PREVIOUS BYPASS SURGERY AS PREDICTOR OF OUTCOME}

In the Non-Enrolled TWENTE population, a history of CABG turned out to be the only predictor of TVF. In fact, the rate of TVF became identical for both patient populations after removing patients with a history of CABG from both patient populations (7.3\% vs. $7.3 \%$; $\mathrm{p}=0.99$ ). Implication of this finding may be that particular attention should be paid to the distribution of patients with a history of CABG between the study arms of comparative DES trials.

Notably, in the randomised TWENTE trial ${ }^{17}$ the proportion of patients with a history of CABG was similar or even higher than in some recent trials with second-generation DES in all-comer populations. ${ }^{18,20}$

\section{Study limitations}

This trial was performed in a high-volume tertiary centre for PCI by five experienced operators with relatively uniform procedural strategies and liberal use of stent postdilatation. ${ }^{17}$ Therefore, generalisation of the results may be limited in other settings.

\section{Conclusion}

Despite some differences in baseline characteristics, non-enrolled and randomised patients did not differ in one-year clinical outcome, which was favourable for both populations and may be related to the second-generation drug-eluting stents used.

\section{Funding}

The Non-Enrolled TWENTE study is an investigator-initiated study that was performed without funding. The randomised TWENTE trial is an investigator-initiated study, supported by equal unrestricted grants from Abbott Vascular and Medtronic.

\section{Conflict of interest statement}

C. von Birgelen is consultant to and has received lecture fees or travel expenses from Abbott Vascular, Medtronic, and Boston Scientific; he received a lecture fee from MSD. All other authors have no conflict of interest to declare.

\section{References}

1. Morice MC, Serruys PW, Sousa JE, Fajadet J, Ban Hayashi E, Perin M, Colombo A, Schuler G, Barragan P, Guagliumi G, Molnar F, Falotico R. A randomized comparison of a sirolimuseluting stent with a standard stent for coronary revascularization. $N$ Engl J Med. 2002;346:1773-80.

2. Moses JW, Leon MB, Popma JJ, Fitzgerald PJ, Holmes DR, O'Shaughnessy C, Caputo RP, Kereiakes DJ, Williams DO, Teirstein PS, Jaeger JL, Kuntz RE. Sirolimus-eluting stents versus standard stents in patients with stenosis in a native coronary artery. N Engl J Med. 2003;349:1315-23.

3. Kastrati A, Mehilli J, Pache J, Kaiser C, Valgimigli M, Kelbaek H, Menichelli M, Sabate M, Suttorp MJ, Baumgart D, Seyfarth M, Pfisterer ME, Schomig A. Analysis of 14 trials comparing sirolimus-eluting stents with bare-metal stents. $N$ Engl J Med. 2007;356:1030-9.

4. Daemen J, Wenaweser P, Tsuchida K, Abrecht L, Vaina S, Morger C, Kukreja N, Juni P, Sianos G, Hellige G, van Domburg RT, Hess OM, Boersma E, Meier B, Windecker S, Serruys PW. Early and late coronary stent thrombosis of sirolimus-eluting and paclitaxel-eluting stents in routine clinical practice: data from a large two-institutional cohort study. Lancet. 2007;369:667-78.

5. Lotan C, Meredith IT, Mauri L, Liu M, Rothman MT; E-Five Investigators. Safety and effectiveness of the Endeavor zotarolimus-eluting stent in real-world clinical practice: 12-month data from the E-Five registry. JACC Cardiovasc Interv. 2009;2: 1227-35.

6. Jensen LO, Maeng M, Thayssen P, Christiansen EH, Hansen KN, Galloe A, Kelbaek H, Lassen JF, Thuesen L. Neointimal hyperplasia after sirolimus-eluting and paclitaxel-eluting stent implantation in diabetic patients. Eur Heart J. 2008;29:2733-41.

7. Tsuchida K, Piek JJ, Neumann FJ, van der Giessen,WJ, Wiemer M, Zeiher AM, Grube E, Haase J, Thuesen L, Hamm CW, Veldhof S, Dorange C, Serruys PW. One-year results of a durable polymer everolimus-eluting stent in de novo coronary narrowings (The SPIRIT FIRST Trial). EuroIntervention. 2005;1:266-72.

8. Serruys PW, Ruygrok P, Neuzner J, Piek JJ, Seth A, Schofer JJ, Richardt G, Wiemer M, Carrie D, Thuesen L, Boone E, MiquelHerbert K, Daemen J. A randomised comparison of an everolimuseluting coronary stent with a paclitaxel-eluting coronary stent:the SPIRIT II trial. EuroIntervention. 2006;2:286-94. 
9. Basalus MW, van Houwelingen KG, Ankone MJ, Feijen J, von Birgelen C. Micro-computed tomographic assessment following extremely oversized partial postdilatation of drug-eluting stents. EuroIntervention. 2010;6:141-8.

10. Basalus MW, Ankone MJ, van Houwelingen KG, de Man FAHF, von Birgelen C. Coating irregularities of durable polymerbased drug-eluting stents as assessed by scanning electron microscopy. EuroIntervention. 2009;5:157-65.

11. Stone GW, Midei M, Newman W, Sanz M, Hermiller JB, Williams J, Farhat N, Mahaffey KW, Cutlip DE, Fitzgerald PJ, Sood P, Su X, Lansky AJ. Comparison of an everolimus-eluting stent and a paclitaxel-eluting stent in patients with coronary artery disease: a randomized trial. JAMA. 2008;299:1903-13.

12. Meredith IT, Worthley S, Whitbourn R, Walters DL, McClean D, Horrigan M, Popma JJ, Cutlip DE, DePaoli A, Negoita M, Fitzgerald PJ. Clinical and angiographic results with the next-generation resolute stent system: a prospective, multicenter, first-in-human trial. JACC Cardiovasc Interv. 2009;2: 977-85.

13. Stone GW, Rizvi A, Newman W, Mastali K, Wang JC, Caputo R, Doostzadeh J, Cao S, Simonton CA, Sudhir K, Lansky AJ, Cutlip DE, Kereiakes DJ. Everolimus-eluting versus paclitaxel-eluting stents in coronary artery disease. N Engl J Med. 2010;362:1663-74.

14. Yeung AC, Leon MB, Jain A, Tolleson TR, Spriggs DJ, Mc Laurin BT, Popma JJ, Fitzgerald PJ, Cutlip DE, Massaro JM, Mauri L. Clinical evaluation of the Resolute zotarolimus-eluting coronary stent system in the treatment of de novo lesions in native coronary arteries: the RESOLUTE US clinical trial. J Am Coll Cardiol. 2011;57:1778-83.

15. Massberg S, Byrne RA, Kastrati A, Schulz S, Pache J, Hausleiter J, Ibrahim T, Fusaro M, Ott I, Schomig A, Laugwitz KL, Mehilli J. Polymer-free sirolimus- and probucol-eluting versus new generation zotarolimus-eluting stents in coronary artery disease: the Intracoronary Stenting and Angiographic Results: Test Efficacy of Sirolimus- and Probucol-Eluting versus Zotarolimus-eluting Stents (ISAR-TEST 5) trial. Circulation. 2011;124:624-32.

16. Meredith IT, Worthley SG, Whitbourn R, Walters D, McClean D, Ormiston J, Horrigan M, Wilkins GT, Hendriks R, Matsis P, Muller D, Cutlip DE. Long-term clinical outcomes with the next-generation Resolute Stent System: a report of the two-year follow-up from the RESOLUTE clinical trial. EuroIntervention. 2010;5:692-7.

17. vonBirgelenC, Basalus WMZ, Tandjung $K$, vanHouwelingen $\mathrm{KG}$, Stoel MG, Louwerenburg JW, Linssen GCM, Saïd SAM, Kleijne MAWJ, Sen H, Löwik MM, van der Palen J, Verhorst PMJ, de Man FHAF. A randomized controlled trial in second-generation zotaroli- mus-eluting Resolute stents versus everolimus-eluting Xience V stents in real-world patients: The TWENTE Trial. J Am Coll Cardiol. 2012;59:1350-61.

18. Serruys PW, Silber S, Garg S, van Geuns RJ, Richardt G, Buszman PE, Kelbaek H, van Boven AJ, Hofma SH, Linke A, Klauss V, Wijns W, Macaya C, Garot P, DiMario C, Manoharan G, Kornowski R, Ischinger T, Bartorelli A, Ronden J, Bressers M, Gobbens P, Negoita M, van Leeuwen F, Windecker S. Comparison of zotarolimus-eluting and everolimus-eluting coronary stents. N Engl J Med. 2010;363:136-46.

19. Windecker S, Serruys PW, Wandel S, Buszman P,Trznadel S, Linke A, Lenk K, Ischinger T, Klauss V, Eberli F, Corti R, Wijns W, Morice MC, di Mario C, Davies S, van Geuns RJ, Eerdmans P, van Es GA, Meier B, Juni P. Biolimus-eluting stent with biodegradable polymer versus sirolimus-eluting stent with durable polymer for coronary revascularisation (LEADERS): a randomised non-inferiority trial. Lancet. 2008;372:1163-73.

20. Kedhi E, Joesoef KS, McFadden E, Wassing J, van Mieghem C, Goedhart D, Smits PC. Second-generation everolimus-eluting and paclitaxel-eluting stents in real-life practice (COMPARE): a randomised trial. Lancet. 2010;375:201-9.

21. Silber S, Windecker S, Vranckx P, Serruys PW. Unrestricted randomised use of two new generation drug-eluting coronary stents: 2-year patient-related versus stent-related outcomes from the RESOLUTE All Comers trial. Lancet. 2011;377:1241-7.

22. Cutlip DE, Windecker S, Mehran R, Boam A, Cohen DJ, van Es GA, Steg PG, Morel MA, Mauri L, Vranckx P, McFadden E, Lansky A, Hamon M, Krucoff MW, Serruys PW. Clinical end points in coronary stent trials: a case for standardized definitions. Circulation. 2007;115:2344-51

23. Vranckx P, Cutlip DE, Mehran R, Kint PP, Silber S, Windecker S, Serruys PW. Myocardial infarction adjudication in contemporary all-comer stent trials: balancing sensitivity and specificity. Addendum to the historical MI definitions used in stent studies. EuroIntervention. 2010;5:871-4.

24. Hordijk-Trion M, Lenzen M, Wijns W, de Jaegere P, Simoons ML, Scholte op Reimer WJM, Bertrand ME, Mercado N, Boersma E. Patients enrolled in coronary intervention trials are not representative of patients in clinical practice: results from the Euro Heart Survey on Coronary Revascularization. Eur Heart J. 2006;27:671-8.

25. de Boer SPM, Lenzen MJ, Oemrawsingh RM, Simsek C, Duckers HJ, van der Giessen WJ, Serruys PW. Evaluating the 'allcomers' design: a comparison of participants in two 'all-comers' PCI trials with non-participants. Eur Heart J. 2011;32:2161-7. 